\title{
A Simple Cost-Effectiveness Analysis of Bilateral Decompression via Unilateral Approach versus Instrumented Total Laminectomy and Fusion for Lumbar Spinal Stenosis
}

\author{
Ali Erhan KAYALAR ${ }^{1}$, Mehmet Resid ONEN¹, Aydin GERILMEZ², Sait NADERI ${ }^{1}$ \\ 'University of Health Sciences, Umraniye Training and Research Hospital, Department of Neurosurgery, Istanbul, Turkey \\ ${ }^{2}$ University of Health Sciences, Haydarpaşa Numune Training and Research Hospital, Department of Neurosurgery, Istanbul, Turkey \\ Corresponding author: Ali Erhan KAYALAR draekayalar@gmail.com
}

\section{ABSTRACT}

AIM: To compare the clinical and economic results of two different surgical approaches (bilateral decompression via unilateral approach and instrumented total laminectomy and fusion) in the treatment of lumbar spinal stenosis.

MATERIAL and METHODS: The clinical, surgical, and economic aspects of 100 surgically treated patients with lumbar spinal stenosis were retrospectively reviewed.

RESULTS: Decompression was performed at 158 levels in 100 patients. The most commonly decompressed levels were L4-5 and L3-4. Significant difference was observed between pre- and postoperative visual analog scale scores in both groups ( $p<0.05)$. In Group 1 (instrumented total laminectomy and fusion), the mean surgery cost was 2539.2 USD (mean procedure cost: 1440.1 USD, mean implant cost: 1099.2 USD). In Group 2 (bilateral decompression via unilateral approach) the mean surgery cost was 998.5 USD. The cost difference was significant $(p<0.05)$.

CONCLUSION: Both instrumented total laminectomy and fusion and bilateral decompression via unilateral approach performed with and without stabilization showed similar clinical results in patients with lumbar spinal stenosis. However, the cost of surgery was found to be 2.5-fold higher in the instrumented total laminectomy and fusion group. This study supports the concept that minimally invasive spine surgery is cost-effective.

KEYWORDS: Cost effectiveness, Economy, Lumbar spinal stenosis, Surgery

ABBREVIATIONS: BDUA: Bilateral decompression via unilateral approach, CT: Computed tomography, MISS: Minimally invasive spinal surgery, MRI: Magnetic resonance imaging, LSS: Lumbar spinal stenosis, VAS: Visual analog scale

\section{INTRODUCTION}

$\mathrm{L}$ umbar spinal stenosis (LSS) may occur as a result of facet joint and ligamentum flavum hypertrophy, disc degenerJation, spinal instability, or a combination of these conditions. In cases without overt instability, neurogenic claudication is the main symptom. The aim of surgical treatment is to eliminate symptoms by sufficiently decompressing the neural elements within the spinal canal. Commonly used modalities for microsurgical treatment are laminectomy $(24,32)$, unilateral laminotomy, bilateral laminotomy, and open door laminoplasty (5). Depending on the extent of decompression, the addition of fusion and stabilization has become more common recently as well. Furthermore, minimally invasive procedures, such as microsurgical or endoscopic decompression and bilateral decompression via unilateral approach (BDUA), have become more common $(2,8,11,18)$. BDUA was first described by Young
Ali Erhan KAYALAR (D): 0000-0001-5717-5889 Mehmet Resid ONEN (D) : 0000-0003-4353-9068
Aydin GERILMEZ Sait NADERI
(1) : 0000-0002-5945-4547

(1) : $0000-0002-6784-4270$ 
et al (36). In this procedure, the facet joints and contralateral neural arch are protected, which decreases scar formation as well as the risk of iatrogenic instability. The aim of the present study was to compare the surgical results and economic costs of instrumented total laminectomy and fusion and BDUA.

\section{MATERIAL and METHODS}

Clinical, surgical, and economic aspects of 100 patients with LSS who underwent surgical intervention were retrospectively reviewed.

\section{Inclusion and Exclusion Criteria}

The primary indication for surgery in this study was neurogenic claudication with or without radicular pain associated with a radiological evidence of LSS. Radiological examination included lumbar magnetic resonance imaging (MRI), computed tomography (CT), dynamic lumbar radiographs, and in selected patients, scoliosis radiographs. Patients with concomitant disorders, such as inflammation, malignancy, degenerative spondylolisthesis, sagittal imbalance, and instability, were excluded from the study.

\section{Patient Classification}

Patients were classified into two groups: Group 1 consisted of cases who underwent total laminectomy, transpedicular stabilization, and posterolateral fusion; Group 2 consisted of patients who underwent BDUA. Leg pain of the patients was evaluated preoperatively and at 8 months postoperatively with a visual analog scale (VAS) using the VAS improvement rate [(preoperative VAS score - postoperative VAS score)/(preoperative VAS score) $\times 100$ ]. In addition, the two groups were compared in terms of operation time, volume of bleeding, length of hospitalization, complications, and economic cost. The mean follow-up period was $16 \pm 6$ months.

\section{Surgical Procedure}

\section{Instrumented Total Laminectomy and Fusion}

All operations were performed under general anesthesia with the patient in the prone position. After fluoroscopy for level localization, a midline skin incision was made and subcutaneous dissection was performed to the lumbosacral fascia, exposing the level(s) of interest and one level above and below. The lumbosacral fascia was opened in the midline and the paravertebral muscles were subperiosteally stripped from the vertebral column bilaterally; a wide dissection was performed to visualize the transverse processes at all levels. First, transpedicular polyaxial screws were placed in each necessary pedicle under fluoroscopic guidance. Then total laminectomy was performed using Kerrison rongeurs and a high-speed drill under microscopic guidance. Following the decompression, the screw system was fixed with rods. Autogenous bone graft was used for fusion. The bone grafts were placed on and between the transverse processes (Figure 1A-D).

\section{BDUA}

All operations were performed under general anesthesia with the patient in the prone position and all stages of the operation were performed using a surgical microscope. Entry was performed with a midline skin incision of approximately 2-3 $\mathrm{cm}$, depending on the number of levels to be decompressed. The procedure was started on the symptomatic side or the side with greater stenosis on the radiographic studies in cases without radiculopathy. After subcutaneous dissection, the lumbosacral fascia was opened in the midline and the paravertebral muscles were stripped subperiosteally off the vertebral column. A Taylor retractor was placed lateral to the facet joint at the level where decompression was to be applied, and a weight of $500 \mathrm{~g}$ was attached. Using a highspeed drill, the upper and lower laminae were removed as far as the free edge of the hypertrophic ligamentum flavum, and the base of the spinous process was removed. Then, by tilting the operating table, the microscope angle was changed to be able to see the contralateral side. With this maneuver, an angle of approximately $60^{\circ}-70^{\circ}$ was achieved and thus good visualization was obtained. At this point, the contralateral ligamentum flavum was excised (Figure 2A-D).

\section{Statistical Analysis}

All statistical analyses were performed using SPSS for Windows 10.0. Descriptive statistical methods (mean, standard deviation) were used for data summarization. For quantitative data, the Wilcoxon sign test was used to compare parameters with non-normal distribution. For qualitative data, comparisons were performed using the Chi-square and McNemar tests. The results were evaluated at a confidence interval of $95 \%$ with statistical significance defined as $p<0.05$.

\section{RESULTS}

\section{Demographics}

There were 50 patients in Group 1 (42 females and 8 males, mean age 56.22 years), and 50 patients in Group 2 (36 females and 14 males, mean age 58.44 years). There was no significant age difference between groups ( $p>0.05)$.

\section{Surgery Levels}

Decompression was performed at 158 levels in 100 patients. The most commonly decompressed levels were L4-5 and L34. In Group 1, single level decompression was performed in 27 patients and multisegmental decompression in 23 patients (mean 1.56 levels), whereas single level was performed in 24 patients and multisegmental in 26 patients in Group 2 (mean 1.56 levels). In Group 1, decompression was performed at a total of 78 levels (L2-3 in 6 patients, L3-4 in 21, L4-5 in 40, and L5-S1 in 11). In Group 2, decompression was performed at a total of 80 levels (L2-3 in 6 patients, L3-4 in 27, L4-5 in 44, and L5-S1 in 3) (Figure 3).

\section{Leg Pain Evaluation}

A significant improvement in the degree of leg pain as a result of surgical decompression was found in all patients. The preoperative mean VAS score decreased from 7.96 \pm 1.08 to $2.88 \pm 0.5$ in Group 1 , and from $7.7 \pm 1.6$ to 2.74 \pm 0.3 in Group 2. The difference between preoperative and postoperative VAS scores was statistically significant in both 

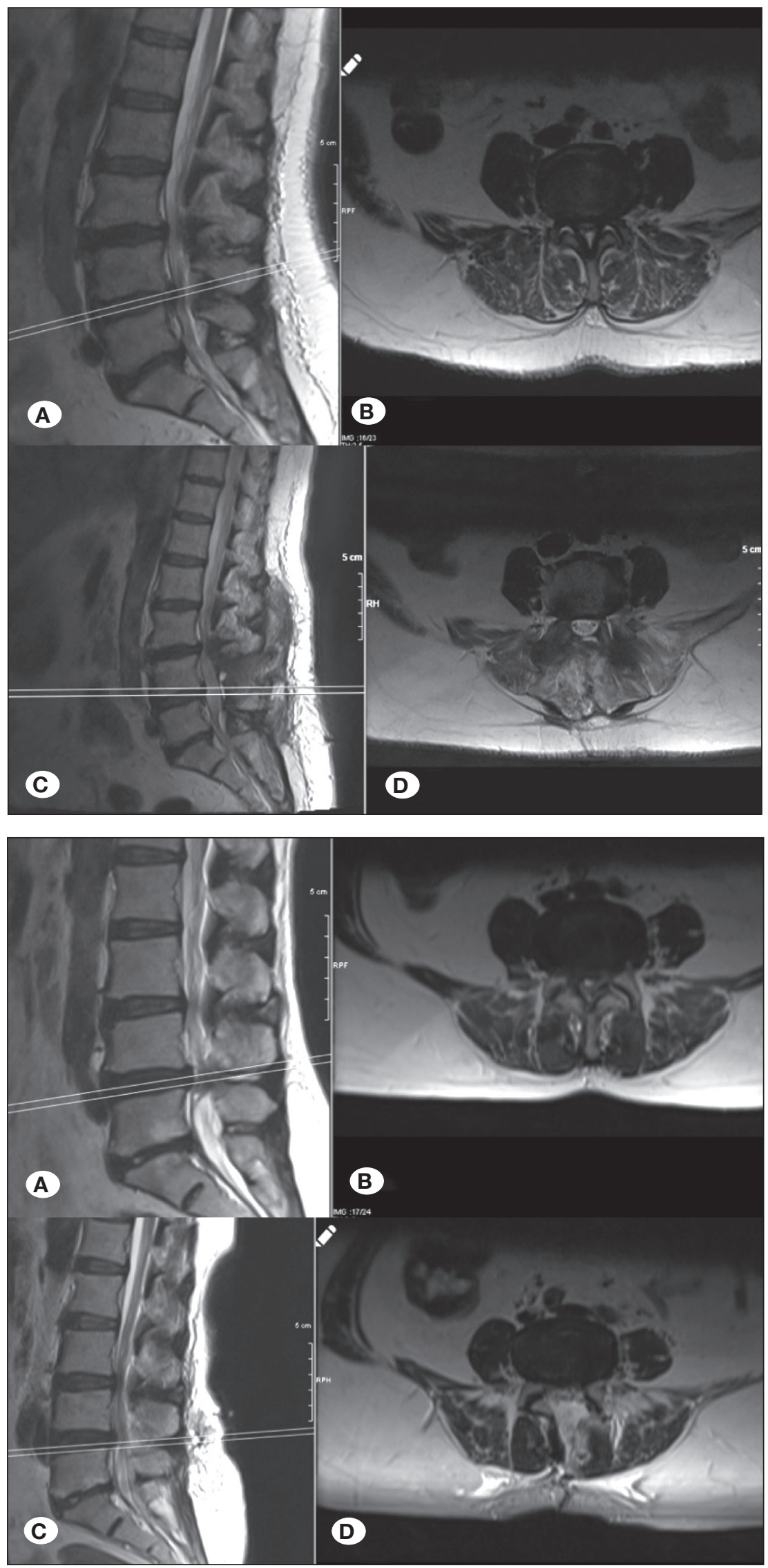

Figure 1: Preoperative $(A, B)$ and postoperative (C,D) sagittal and axial T2W-MR images of a case with $L 4-5$ lumbar spinal stenosis who underwent L4 total laminectomy with L4-L5 pedicle screw instrumentation.
Figure 2: Preoperative $(\mathbf{A}, \mathbf{B})$ and postoperative $(C, D)$ sagittal and axial T2W-MR images of a case with L4-5 lumbar spinal stenosis who underwent bilateral decompression via unilateral approach. 
groups $(p=0.000)$. The VAS improvement rate was $63.8 \%$ in Group 1 and $64.4 \%$ in Group 2 (Figure 4).

\section{Operating Time}

The operating time (time from initial incision to final skin closure) was $186 \pm 75$ minutes in Group 1 and $75.4 \pm 30$ minutes in Group 2. The observed difference was statistically significant $(p<0.05)$. We ignored all the periods of time lost in monitoring after intubation, arterial catheterization, attaching the catheter, positioning the patient, and positioning for preoperative fluoroscopy imaging and postoperative supine positioning, and late and early awakening.

\section{Length of Hospitalization}

Mean duration of postoperative hospitalization was 2.8 days in Group 1, and 1.2 days in Group 2. The observed difference between groups was statistically significant $(p<0.05)$. In addition, we found that as the number of levels that underwent decompression increased, the length of hospitalization also increased.

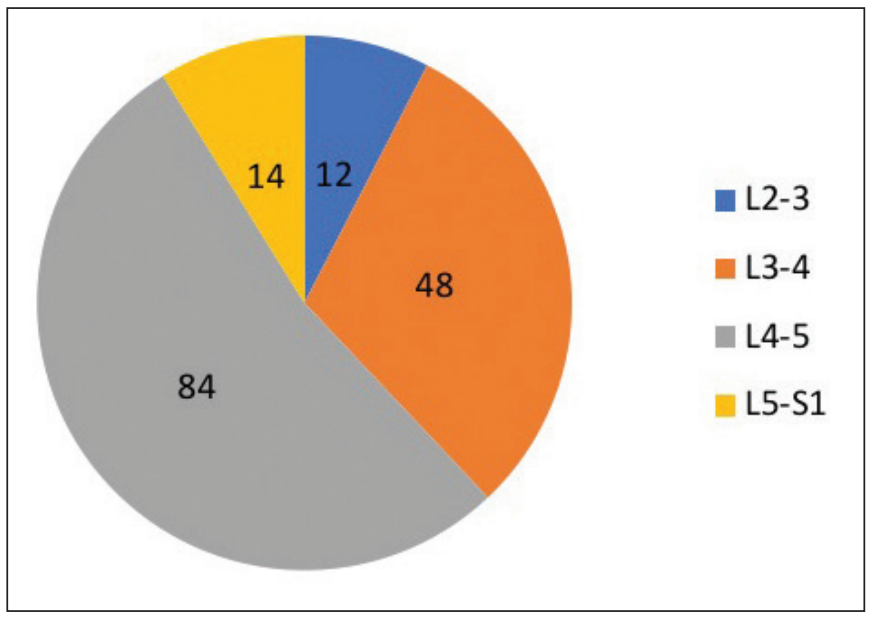

Figure 3: Number of levels operated on according to the pathological level.

\section{Blood Loss}

Blood loss was $400 \pm 85 \mathrm{~mL}$ in Group 1 and $90 \pm 35 \mathrm{~mL}$ in Group 2. The observed difference was statistically significant $(p<0.05)$.

\section{Cost Analysis}

In Group 1, the mean cost of surgery was 1440.1 USD and the mean implant cost was 1099.2 USD, for a mean total cost of 2539.2 USD. In Group 2, the mean cost of surgery was 998.5 USD. The difference between groups was statistically significant $(p<0.05)$. All cost analysis data are presented in Table I.

\section{Complications}

During long-term follow-up in Group 1, adjacent segment disease developed in one patient, who then underwent further decompression and extension of the fusion and instrumentation. In Group 2, a dural tear occurred in one patient that was repaired with sutures and fibrin glue; no cerebrospinal fluid fistula developed during follow-up. Radicular complaints recurred during long-term follow-up in two patients who then underwent additional microdiscectomy.

\section{DISCUSSION}

This study showed the effectiveness of both laminectomy with fusion and BDUA in the surgical treatment of LSS and confirmed that BDUA is associated with lower cost, shorter postoperative hospitalization, and less blood loss than total laminectomy and fusion. The aim of surgery in LSS is improvement in neurogenic claudication and relief of pain. The standard treatment for spinal stenosis is total or hemilaminectomy. However, such a decompression may be associated with disruption of the supraspinous and interspinous ligament complexes, as well as disruption of the facet joints, leading to spinal instability $(9,24,25,28,30,34)$. Therefore, the addition of instrumented fusion to decompression by many surgeons has become common practice $(7,13)$. BDUA was developed

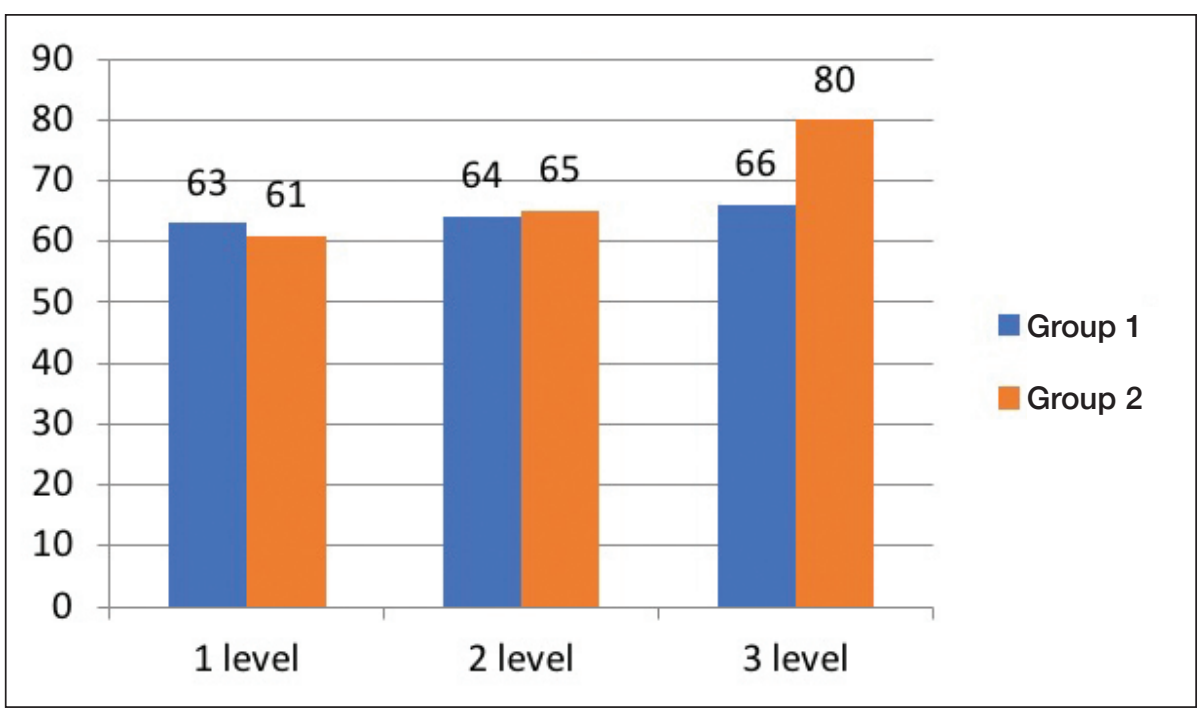

Figure 4: Preoperative - postoperative VAS changes according to the number of levels decompressed. 
Table I: Comparison of the Results Between the Two Groups

\begin{tabular}{|c|c|c|c|c|c|c|c|}
\hline & \multirow{2}{*}{$\begin{array}{c}\text { Number of } \\
\text { cases }\end{array}$} & \multicolumn{2}{|c|}{ Pain relief (VAS) } & \multirow{2}{*}{$\begin{array}{l}\text { Length of } \\
\text { Hospital Stay } \\
\text { (days) }\end{array}$} & \multirow{2}{*}{$\begin{array}{l}\text { Blood Loss } \\
\text { (mL) }\end{array}$} & \multirow{2}{*}{$\begin{array}{l}\text { Operation time } \\
(\min )\end{array}$} & \multirow{2}{*}{$\begin{array}{c}\text { Cost analysis } \\
\text { (US Dollar) }\end{array}$} \\
\hline & & Preoperative & Postoperative & & & & \\
\hline Group I & 50 (42 F; 8 M) & $7.96 \pm 1.08$ & $2.88 \pm 0.5$ & 2.8 & $400 \pm 85$ & $186 \pm 75$ & 1440.1 \\
\hline Group II & 50 (36 F; 14 M) & $7.7 \pm 1.6$ & $2.74 \pm 0.3$ & 1.2 & $90 \pm 35$ & $75.4 \pm 30$ & 2539.2 \\
\hline \multicolumn{2}{|c|}{ Statistical Analysis } & \multicolumn{2}{|c|}{$p>0.05$} & $p<0.05$ & $p<0.05$ & $p<0.05$ & $p<0.05$ \\
\hline
\end{tabular}

to minimize instability due to iatrogenic ligament and facet joint disruption, and has become an effective alternative. By protecting a significant proportion of the facet joints and ligaments, the BDUA technique reduces the risk of instability, thus the addition of instrumented fusion to the procedure may not be needed. Previous studies have reported good shortterm, mid-term, and long-term clinical results with BDUA $(12,17,27,29,34)$. However, as the follow-up period became longer, the success rate decreased. Cavusoglu et al. reported a $94 \%$ patient satisfaction rate and $96 \%$ recovery rate in a study of BDUA patients with an 18-24 month follow-up period (4). In a study by Yaman et al. that compared the clinical and radiological results of classic laminectomy and BDUA at 6 and 12 months after surgery, no difference was found between the two procedures in terms of leg pain VAS scores, whereas back pain VAS scores of the BDUA patients were significantly lower (35). A randomized clinical study by Mobbs et al. that compared BDUA with open decompression in 79 patients found that BDUA was as effective as open decompression in terms of improvement in Oswestry Disability Index scores (6). Similarly, in a study by Park et al. ipsilateral and contralateral canal decompression using unilateral laminectomy were compared; the VAS improvement rate was $75.4 \%$ on the ipsilateral side and $73.7 \%$ on the contralateral side. The slight difference was not statistically significant (19). These studies and others suggest that BDUA is effective in the surgical treatment of LSS in terms of unilateral and contralateral leg pain and low back pain. In the current study, no statistically significant difference was found between Group 1 and Group 2 with respect to postoperative leg VAS scores, suggesting that the BDUA procedure is as successful as classic laminectomy in relieving leg pain. Back pain VAS scores of the BDUA patients were lower. We believe that this is due to less muscle stripping and retraction and preservation of the spinous processes and interspinous and supraspinous ligament complexes. The current study also showed that BDUA was associated with less blood loss, which agrees with previously published studies by Cavusoglu et al. (4), and Krut'ko (14). Less back pain and less blood loss are two advantages of BDUA in LSS surgery.

Other advantages associated with BDUA are shorter hospitalization time and lower cost. Although these advantages have been reported in many studies, debate remains regard- ing whether minimally invasive spinal surgery (MISS) is more cost-effective than open surgery. This is because MISS techniques may require initial capital expenditures for imaging (C-arm, or O-arm) and the surgery itself (microscope, robotics, endoscope, and microinstruments). However, after initial expenditures, MISS techniques are associated with shorter hospitalization and faster return to work, resulting in better overall cost effectiveness in the long-term. Most cost-related studies have reported the costs of fusion techniques and confirmed the superiority of minimally invasive interbody fusion in terms of hospitalization rate, anesthesia time, and lower direct hospital costs. However, there are also several studies on the economic aspects of purely decompressive procedures $(3,10$, $16,22,23,26,33)$. Udeh et al. compared laminectomy and minimally invasive decompression and reported that minimally invasive decompression was more cost-effective (43,760 USD vs. 125,985 USD) (31). Parker et al. compared conservative care, laminectomy, and interspinous spacer in the treatment of LSS and reported that laminectomy was more cost-effective than both interspinous spacer and conservative care (20-22). In other studies, the cost of decompression was compared with the cost of decompression and instrumented fusion. Kuntz et al. compared the costs and benefits of laminectomy alone to laminectomy plus lumbar fusion for patients with degenerative lumbar spondylolisthesis and LSS. As a result, they reported cost effectiveness of laminectomy alone when compared with decompression with instrumented fusion (15). A similar result was noted by Alvin et al., who reported that decompression with instrumented fusion was inferior to decompression alone in terms of cost effectiveness 1 year after surgery in patients with grade I degenerative spondylolisthesis (1). Our cost-related findings are in line with the previously reported results, however our study is limited, as a more detailed costeffectivity analysis could not be performed.

\section{CONCLUSION}

Laminectomy with fusion and BDUA for LSS have comparable clinical results after surgery, but BDUA is superior in terms of cost effectiveness (Table II). BDUA was found to be more cost-effective due to its lesser surgical cost, shorter hospital stay, and reduced need for transfusion. 
Table II: Summary of the Previously Published (2012 - 2016) Literature

\begin{tabular}{|c|c|c|c|}
\hline Comparison & Author & Year & Result \\
\hline MISS vs. Open TLIF & Parker et al. & 2012 & $\begin{array}{l}\text { MIS-TLIF allows patients to leave the hospital sooner, achieve narcotic } \\
\text { independence sooner, and return to work sooner than open-TLIF. In our } \\
\text { experience, MIS- versus open-TLIF is a cost reducing technology in the } \\
\text { surgical treatment of medically refractory low-back and leg pain from grade } \\
\text { I lumbar spondylolisthesis. }\end{array}$ \\
\hline MISS vs. Open TLIF & Parker et al. & 2014 & $\begin{array}{l}\text { MIS-TLIF may represent a valuable and cost-saving advancement from a } \\
\text { societal and hospital perspective. }\end{array}$ \\
\hline MISS vs. Open TLIF & Singh et al. & 2014 & $\begin{array}{l}\text { MIS-TLIF technique demonstrated significant reductions of operative time, } \\
\text { LOS, anesthesia time, VAS scores, and EBL compared with the open } \\
\text { technique. This reduction in perioperative parameters translated into lower } \\
\text { total hospital costs over a } 60 \text {-day perioperative period. }\end{array}$ \\
\hline
\end{tabular}

MAS tubular discectomy

with conventional

md, minimal access

TLIF versus open

TLIF, and multilevel

hemilaminectomy via

MAS versus open

approach.

Circumferential fusions vs. posterolateral fusions

Ghogawala et al.

(Guideline

update)
2014 The included cost-effectiveness studies generally supported no significant differences between open surgery and MAS lumbar approaches. Much of the evidence lacked details on methodology for modeling, related assumptions, justification of economic model chosen, and sources and types of included costs and consequences. The follow-up periods were highly variable, indirect costs were not frequently analyzed or reported, and many of the studies were conducted by a single group, thereby limiting generalizability. Prospective studies are needed to define differences and optimal treatment algorithms.

Recent costanalyses have demonstrated the long-term benefits of 2014 circumferential fusions over posterolateral fusions (This study showed an incremental savings of $\$ 49,306$ per QALY following a circumferential fusion compared with a posterolateral fusion.)

MISS is a more cost-effective surgical procedure for lumbar spinal fusion in comparison with traditional OS in both the United Kingdom and Italy

Conservative care (CC)

vs. laminectomy (DS) vs. Parker et al. 2015 DS was more cost effective than spacer and CC

the interspinous spacer

MI-TLIF vs. open-TLIF Phan et al. $2015 \quad$ invasive compared with open surgical approaches for TLIF

(weighted mean difference (WMD) \$2820 61\%)

Laminectomy vs.

MISS

Udeh et al. 2015

MISS was more cost effective 43.760 S vs. $125.985 \mathrm{~S}$

At a cost per QALY threshold of $\$ 100,000$ and using SF-6D-based QALYs, the authors found that TLIF would be cost-prohibitive compared with PSF at a surgical cost of $\$ 4830$ above that of PSF. However, with EQ5D-based QALYs, TLIF would become cost-prohibitive at an increased TLIF vs. PSF Carreon et al. 2016 surgical cost of $\$ 2960$ relative to that of PSF. With the 2014 US per capita gross domestic product of $\$ 53,042$ as a more stringent cost-effectiveness threshold, TLIF would become cost-prohibitive at surgical costs $\$ 2562$ above that of PSF with SF-6D-based QALYs or at a surgical cost exceeding that of PSF by $\$ 1570$ with EQ-5D-derived QALYs. 


\section{REFERENCES}

1. Alvin MD, Lubelski D, Abdullah KG, Whitmore RG, Benzel EC, Mroz TE: Cost-utility analysis of instrumented fusion versus decompression alone for Grade I L4-L5 spondylolisthesis at 1-year follow-up: A pilot study. Clin Spine Surg 29:80-86, 2016

2. Aryanpur J, Ducker T: Multilevel lumbar laminotomies: An alternative to laminectomy in the treatment of lumbar stenosis. Neurosurgery 26:429-432, 1990

3. Carreon LY, Glassman SD, Ghogawala Z, Mummaneni PV, McGirt MJ, Asher AL: Modeledcost-effectiveness of transforaminal lumbar interbody fusion compared with posterolateral fusion for spondylolisthesis using N(2)QOD data. J Neurosurg Spine 24: 916-921, 2016

4. Cavusoglu H, Turkmenoglu O, Kaya RA, Tuncer C, Colak I, Sahin Y, Aydin Y: Efficacy of unilateral laminectomy for bilateral decompression in lumbar spinal stenosis. Turk Neurosurg 17:100-108, 2007

5. Chatani K: A novel surgical approach to the lumbar spine involving hemilateral split-off of the spinous process to preserve the multifidus muscle: Technical note. J Neurosurg Spine 24:694-699, 2016

6. Choi WS, Oh CH, Ji GY, Shin SC, Lee JB, Park DH, Cho $\mathrm{TH}$ : Spinal canal morphology and clinical outcomes of microsurgical bilateral decompression via a unilateral approach for lumbar spinal canal stenosis. Eur Spine J 23: 991-998, 2014

7. Deyo RA, Nachemson A, Mirza SK: Spinal fusionsurgery-the case for restraint. N Engl J Med 350:722-726, 2004

8. Dirksmeier P, Parsons IM, Kang J: Microendoscopic and open laminotomy and discectomy in lumbar disc disease. Semin Spine Surg 11:138-146, 1999

9. Fox MW, Onofrio BM, Hanssen AD: Clinical outcomes and radiological instability following decompressive lumbar laminectomy for degenerative spinal stenosis: A comparison of patients undergoing concomitant arthrodesis versus decompressional one. J Neurosurg 85:793-802, 1996

10. Ghogawala Z, Whitmore RG, Watters WC 3rd, Sharan A, Mummaneni PV, Dailey AT, Choudhri TF, Eck JC, Groff MW, Wang JC, Resnick DK, Dhall SS, Kaiser MG: Guideline update for the performance of fusion procedures for degenerative disease of the lumbar spine. Part 3: Assessment of economic outcome. J Neurosurg Spine 21:14-22, 2014

11. Herkowitz H, Kurz L: Degenerative lumbar spondylolisthesis with spinal stenosis. J Bone Joint 73:802-808: 1991

12. Ji YC, Kim YB, Hwang SN, Park SW, Kwon JT, Min BK: Efficacy of unilateral laminectomy for bilateral decompression in elderly lumbar spinal stenosis. J Korean Neurosurg Soc 37: 410-415, 2005

13. Korovessis P, Papazisis Z, Koureas G, Lambiris E: Rigid, semirigid versus dynamic instrumentation for degenerative lumbar spinal stenosis: A correlative radiological and clinical analysis of short-term results. Spine 29:735-742, 2004

14. Krut'ko AV: Results of decompressive stabilizing procedures via unilateral approach in lumbar spinal stenosis. Zh Vopr Neirokhir Im N N Burdenko 76:33-40, 2012
15. Kuntz KM, Snider RK, Weinstein JN, Pope MH, Katz JN: Cost-effectiveness of fusion with and without instrumentation for patients with degenerative spondylolisthesis and spinal stenosis. Spine 25:1132-1139, 2000

16. Lubelski D, Mihalovich KE, Skelly AC, Fehling MG, Harrop JS, Mummaneni OV, Wang MY, Steinmetz MP: Is minimal access spine surgery more cost-effective than conventional spine surgery? Spine 39 (22 Suppl 1):65-74, 2014

17. Mariconda M, Fava R, Gatto A, Longo C, Milano C: Unilateral laminectomy for bilateral decompression of lumbarspinalstenosis: A prospective comparative study with conservatively treated patients. J Spinal Disord Tech 15:3946, 2002

18. Palmer S, Turner R, Palme R: Bilateral decompression of lumbar spinal stenosis involving a unilateral approach with microscope and tubular retractor system. J Neurosurg 97:213217, 2002

19. Park WB, Hong JT, Lee SW, Sung JH, Yang SH, Kim IS: Clinical and radiological comparison between ipsilateral and contralateral side canal decompression using an unilateral laminotomy approach. Korean J Spine 13:41-46, 2016

20. Parker SL, Adogwa O, Bydon A, Cheng J, McGirt MJ: Costeffectiveness of minimally invasive versus open transforaminal lumbar interbody fusion for degenerative spondylolisthesis associated low-back and leg pain over two years. World Neurosurg 78:178-184, 2012

21. Parker SL, Mendenhall SK, Shau DN, Zucherman SL, Godil SS, Cheng JS, McGirt MJ: Minimally invasive versus open transforaminal lumbar interbody fusion for degenerative spondylolisthesis: Comparative effectiveness and cost-utility analysis. World Neurosurg 82:230-238, 2014

22. Parker SL, Anderson LH, Nelson T, Patel VV: Costeffectiveness of three treatment strategies for lumbar spinal stenosis: Conservative care, laminectomy, and the superioninterspinous spacer. Int J Spine Surg 9:9-28, 2015

23. Phan K, Hogan JA, Mobbs RJ: Cost-utility of minimally invasive versus open transforaminal lumbar interbody fusion: Systemic review and economic evaluation. Eur Spine J 24: 2503-2513, 2015

24. Phan K, Mobbs RJ: Minimally invasive versus open laminectomy for lumbar stenosis: A systematic review and meta-analysis. Spine 41:91-100, 2016

25. Prestar FJ: Morphology and function of the interspinal ligaments and the supraspinal ligament of the lumbar portion of the spine. Morphol Med 2:53-58, 1982

26. Singh K, Nandyala SV, Marquez-Lara A, Fineberg SJ, Oglesby M, Pelton MA, Andersson GB, Isayeva D, Jegier BJ, Phillips FM: A perioperative cost analysis comparing single-level minimally invasive and open transforaminal lumbar interbody fusion. Spine J 14:1694-1701, 2014

27. Spetzger $U$, Bertalanffy $H$, Reinges $M H$, Gilsbach JM: Unilateral laminotomy for bilateral decompression of lumbar spinal stenosis. Part II: Clinical experiences. Acta Neurochir 139:397-403, 1997

28. Thomas NW, Rea GL, Pikul BK, Mervis LJ, Irsik R, McGregor JM: Quantitative out come and radiographic comparisons between laminectomy and laminotomy in the treatment of acquired lumbar stenosis. Neurosurgery 41:567-575, 1997 
29. Thome C, Zevgaridis D, Leheta O, Bazner H, PocklerSchoniger C, Wohrle J, Schmiedek P: Outcome after less-invasive decompression of lumbar spinal stenosis: A randomize decomparison of unilateral laminotomy, bilateral laminotomy, and laminectomy. J Neurosurg Spine 3:129-141, 2005

30. Tsai RY, Yang RS, Bray RS Jr: Microscopic laminotomies for degenerative lumbar spinal stenosis. J Spinal Disord 11:389394, 1998

31. Udeh BL, Costandi S, Dalton JE, Ghosh R, Yousef H, Mekhail $\mathrm{N}$ : The 2-year cost-effectiveness of 3 options to treat lumbar spinal stenosis patients. Pain Pract 15:107-116, 2015

32. Usman M, Ali M, Khanzada K, Ishaq M, Naeem-ul-Haq, Aman R: Unilateral approach for bilateral decompression of lumbar spinal stenosis: A minimal invasive surgery. J Coll Physicians Surg Pak 23:852-856, 2013
33. Vertuani S, Nilsson J, Borgman B, Buseghin G, Leonard C, Assietti R, Quraishi NA: A cost-effectiveness analysis of minimally invasive versus open surgery techniques for lumbar spinal fusion in Italy and the United Kingdom. Value Health 18: 810-816, 2015

34. Weiner BK, Walker M, Brower RS, McCulloch JA: Micro decompression for lumbar spinal canal stenosis. Spine 24: 2268-2272, 1999

35. Yaman O, Ozdemir N, Dagli AT, Acar E, Dalbayrak S, Temiz C: A comparison of bilateral decompression via unilateral approach and classic laminectomy in patients with lumbar spinal stenosis: A retrospective clinical study. Turk Neurosurg 25: 239-245, 2015

36. Young S, Veerapen R, O'Laoire SA: Relief of lumbar canal stenosis using multilevel subarticular fenestrations as an alternative to wide laminectomy: Preliminary report. Neurosurgery 23:628-633, 1988 